\title{
The world is coming to Canada in 2005!
}

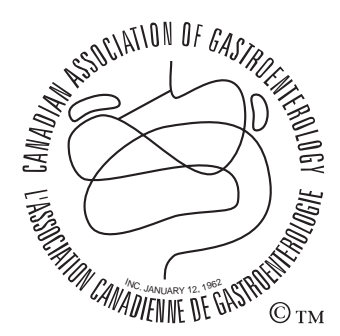

En français voir page 270

\author{
Philip M Sherman MD FRCPC \\ President, the Canadian Association of Gastroenterology
}

$\mathrm{O}$ $n$ behalf of the Canadian Association of Gastroenterology (CAG), the Canadian Bid Federation has been lobbying vigorously over the past several years to secure the meeting of the World Congress of Gastroenterology in 2005. I am delighted to be able to let you know that there was overwhelming support for the Canadian bid. As a result, this international meeting will take place in Montreal, Quebec, during the first several weeks of September in 2005. We hope that members of the CAG will mark this date in their calendars, and plan to attend the meeting and participate in the scientific sessions and social events.

To support the meeting, the CAG will not hold a Canadian Digestive Disease Week in 2005. The highly successful and internationally recognized annual endoscopy course run by the Wellesley/St Michael's Hospital therapeutic endoscopy group in Toronto has kindly agreed to run daily sessions at the meeting in Montreal via satellite. Planning is also underway to hold additional prestigious satellite meetings in conjunction with the World Congress of Gastroenterology in 2005.

This is an opportune time to thank each of the members of the Canadian Bid Federation for their efforts on behalf of the membership of the CAG. It is through their work that we were successful in this bid proposal. I wish to extend special thanks to Dr Richard Fedorak in his role as president of the Canadian Bid Federation. Richard has worked tirelessly on this project. His reward will be more hard work in the planning of the meeting, which is only some two and a half years hence! I also would like to acknowledge the support of the city of Montreal, the province of Quebec, and the federal government through the rigours of the bid process.

Dr John Wallace will lead the development of the scientific program in consultation with the leadership of the
World Congress of Gastroenterology and an international advisory panel. The meeting will highlight recent advances in gastroenterology, endoscopy, hepatology and nutrition. This meeting will provide an international forum to highlight Canadian talent, with an emphasis on young investigators. We are committed to supporting the international content of the meeting. There will be moderators, discussants, debaters and speakers in attendance from every continent across the planet. There will be an

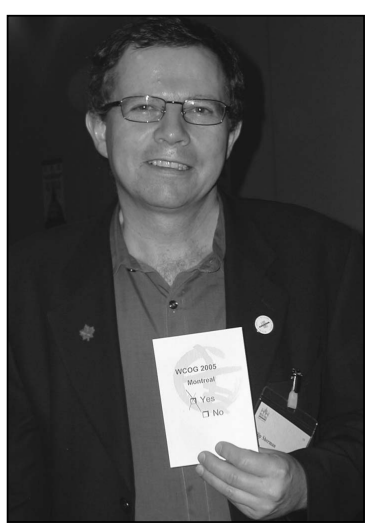

Dr Philip Sherman, President of the Canadian Association of Gastroenterology, casts his vote to hold the 2005 World Congress of Gastroenterology in Montreal, Quebec emphasis on the participation of young investigators from developing nations.

In partnership with our international colleagues in the World Congress of Gastroenterology, the CAG and the Canadian Bid Federation are committed to fiscal responsibility in the planning and staging of this international forum. We will strive to contain costs, encourage international participation and provide an endowment to support CAG-related activities in the long term.

We look forward to the support of the CAG membership in the efforts that will be required over the next two years in putting together what I envisage as the best World Congress of Gastroenterology ever held. Please do not hesitate to contact any one of the members of the Bid Federation with comments, suggestions and feedback about this initiative. 


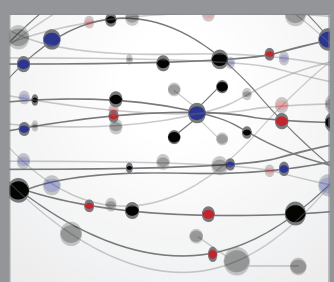

The Scientific World Journal
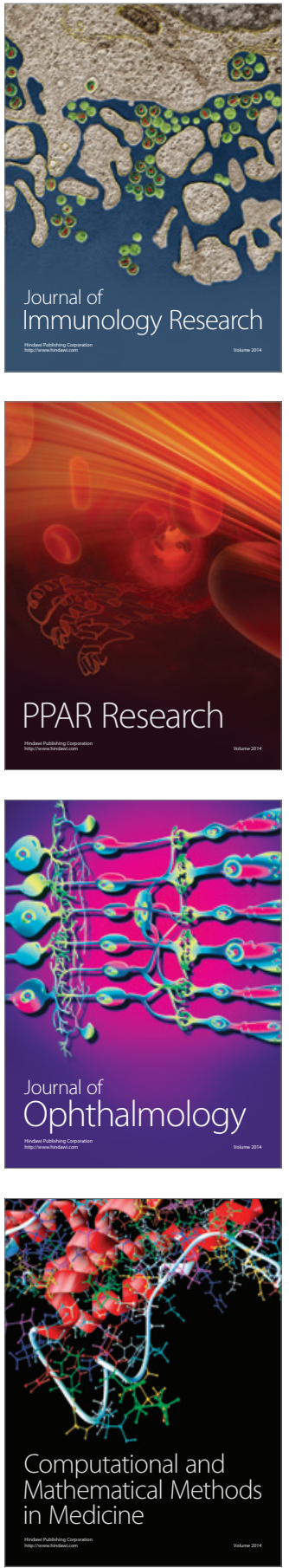

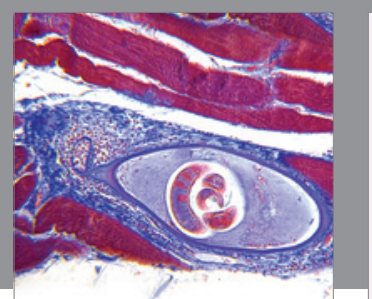

Gastroenterology Research and Practice

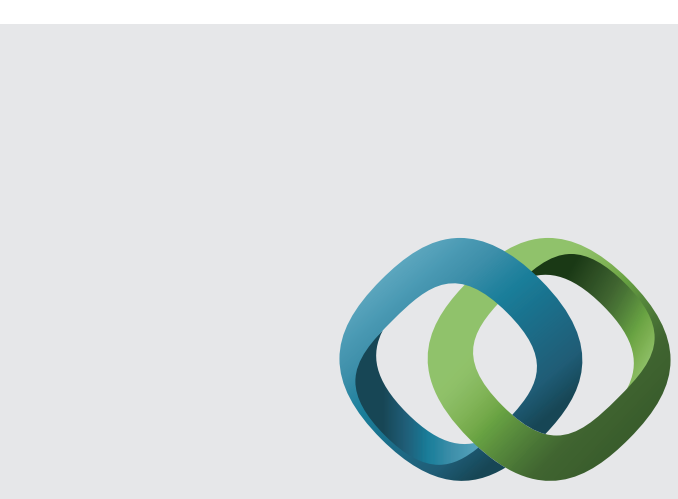

\section{Hindawi}

Submit your manuscripts at

http://www.hindawi.com
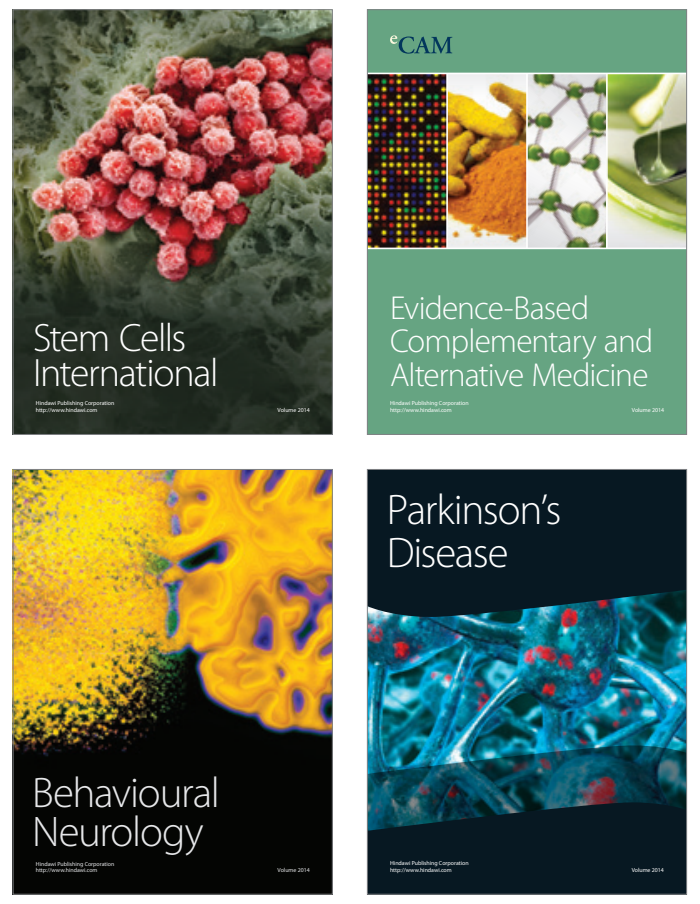
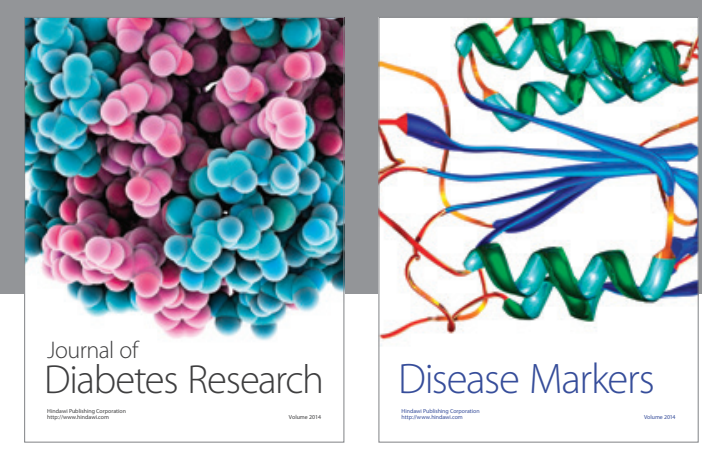

Disease Markers
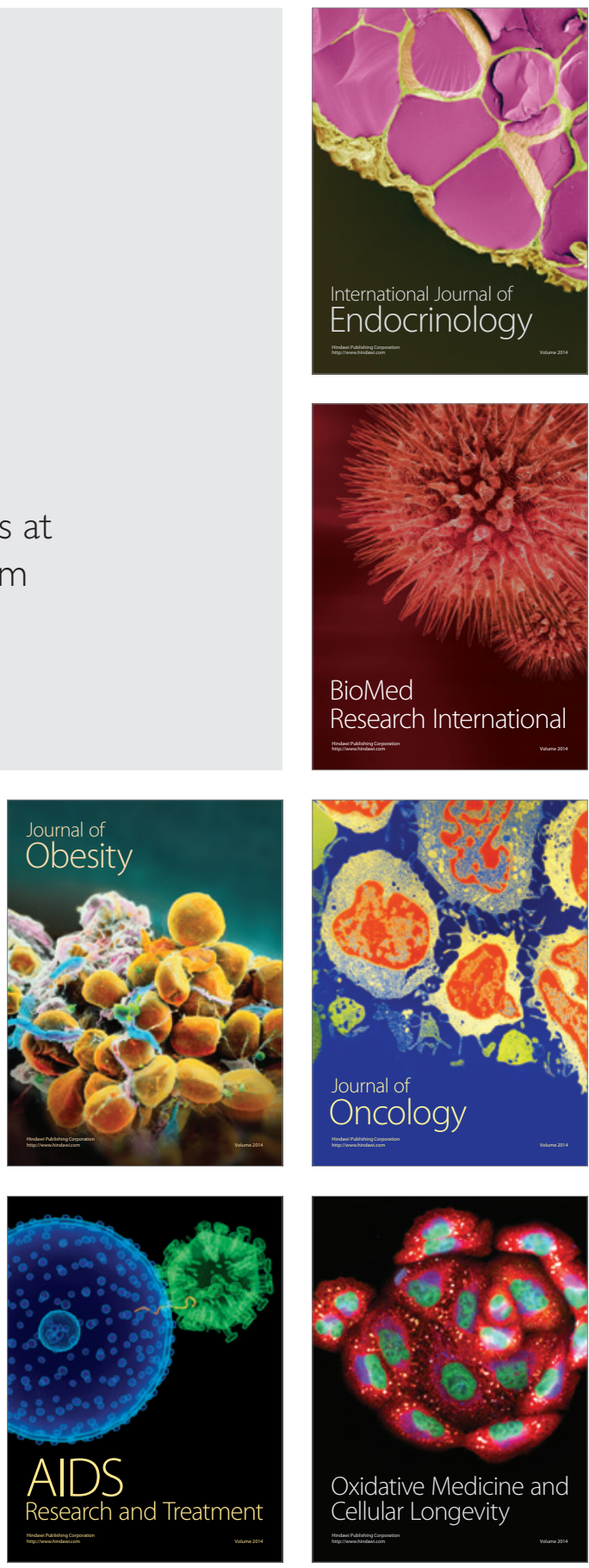